NATIONAL LABORATORY

\title{
Methodology for Determining Radiation Portal Monitor Availability from Daily Files
}

\section{December 2012}

Prepared by

Tyler Guzzardo

Alex Enders

Scott Alcala

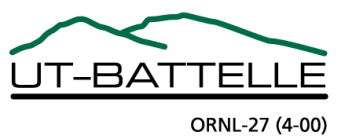




\title{
DOCUMENT AVAILABILITY
}

Reports produced after January 1, 1996, are generally available free via the U.S. Department of Energy (DOE) Information Bridge.

Web site http://www.osti.gov/bridge

Reports produced before January 1, 1996, may be purchased by members of the public from the following source.

\author{
National Technical Information Service \\ 5285 Port Royal Road \\ Springfield, VA 22161 \\ Telephone 703-605-6000 (1-800-553-6847) \\ TDD 703-487-4639 \\ Fax 703-605-6900 \\ E-mail info@ntis.gov \\ Web site http://www.ntis.gov/support/ordernowabout.htm
}

Reports are available to DOE employees, DOE contractors, Energy Technology Data Exchange (ETDE) representatives, and International Nuclear Information System (INIS) representatives from the following source.

Office of Scientific and Technical Information

P.O. Box 62

Oak Ridge, TN 37831

Telephone 865-576-8401

Fax 865-576-5728

E-mail reports@osti.gov

Web site http://www.osti.gov/contact.html

This report was prepared as an account of work sponsored by an agency of the United States Government. Neither the United States Government nor any agency thereof, nor any of their employees, makes any warranty, express or implied, or assumes any legal liability or responsibility for the accuracy, completeness, or usefulness of any information, apparatus, product, or process disclosed, or represents that its use would not infringe privately owned rights. Reference herein to any specific commercial product, process, or service by trade name, trademark, manufacturer, or otherwise, does not necessarily constitute or imply its endorsement, recommendation, or favoring by the United States Government or any agency thereof. The views and opinions of authors expressed herein do not necessarily state or reflect those of the United States Government or any agency thereof. 


\title{
METHODOLOGY FOR DETERMINING RADIATION PORTAL MONITOR AVAILABILITY FROM DAILY FILES
}

\author{
Tyler Guzzardo \\ Alex Enders \\ Scott Alcala
}

Date Published: December 2012

\author{
Prepared by \\ OAK RIDGE NATIONAL LABORATORY \\ Oak Ridge, Tennessee 37831-6283 \\ managed by \\ UT-BATTELLE, LLC \\ for the \\ U.S. DEPARTMENT OF ENERGY \\ under contract DE-AC05-00OR22725
}





\section{CONTENTS}

\section{Page}

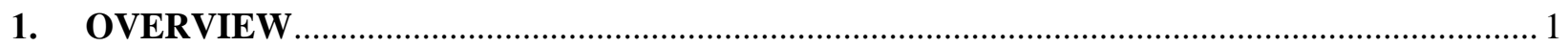

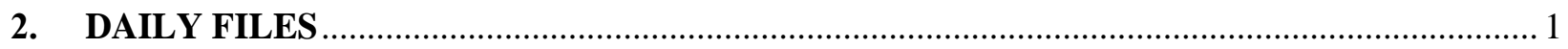

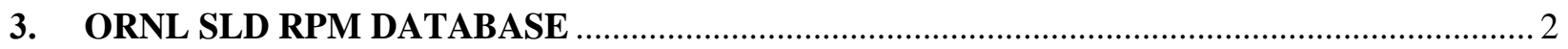

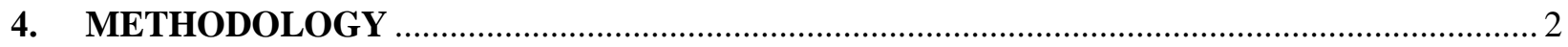

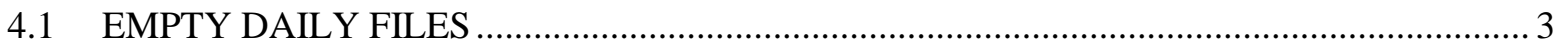

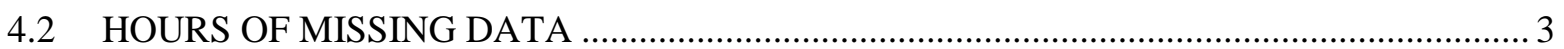

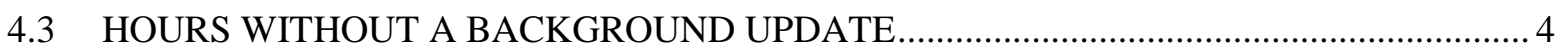

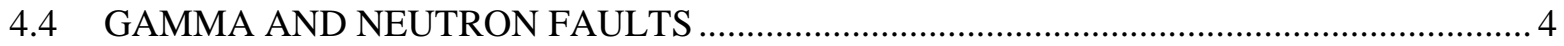

4.5 TWO NEUTRON SIGNALS MEASURING ZERO ..................................................... 5

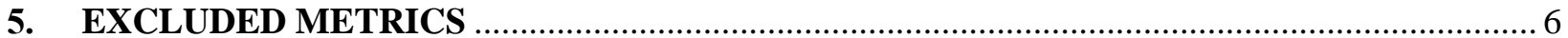

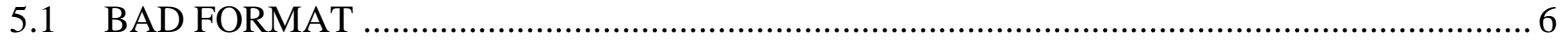

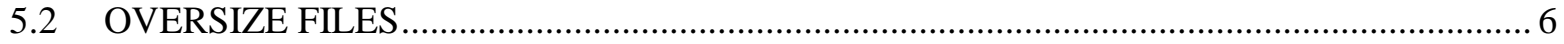

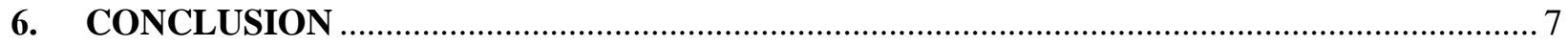

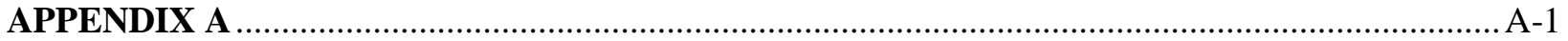

A.1 CALCULATION OF MINIMUM REQUIRED NEUTRON SIGNAL LINES .................. A-3

A.2 PROGRAMMING SOURCE CODE FOR ALGORITHM ............................................... A-5 



\section{OVERVIEW}

The Second Line of Defense (SLD) Program works with partner countries to enhance their capabilities in deterring, detecting, and interdicting the illicit trafficking of nuclear and radiological materials through international borders by providing radiation detection equipment and related training. With agreement from SLD partner countries, the program collects daily file data from installed TSA Systems pedestrian, conveyor, vehicle, and rail radiation portal monitors (RPMs). ${ }^{1}$ Analysis of the data can provide information related to the state of health and configuration of the radiation monitoring equipment. By analyzing this data from the field over long periods of time, the program is able to determine valuable information such as the general reliability of the deployed equipment. In order to characterize the program's overall effectiveness, data from daily files is used to determine the availability of RPMs that submit daily files to Oak Ridge National Laboratory (ORNL). Availability in this context is the proportion of time the RPM is in a functioning condition. The RPM is available when all the components of the system are functioning properly, thereby allowing the proper functioning of the RPM as a whole. This document explains the methodology and assumptions used to arrive at an availability metric for the RPMs from which ORNL receives data.

\section{DAILY FILES}

Data from the RPMs is stored in the form of daily files that contain a log of operations performed by the RPM for 24 hours. Each line in the daily file contains a two-character code that defines the contents of the line, followed by several data elements that pertain to the two-character code. The definitions of each type of two-character code are listed in Fig. 1. Some of the basic information contained in the daily files includes gamma and neutron background count rates, gamma and neutron signal count rates, alarm conditions, current RPM settings, and fault conditions. Although numerous countries send data to ORNL,

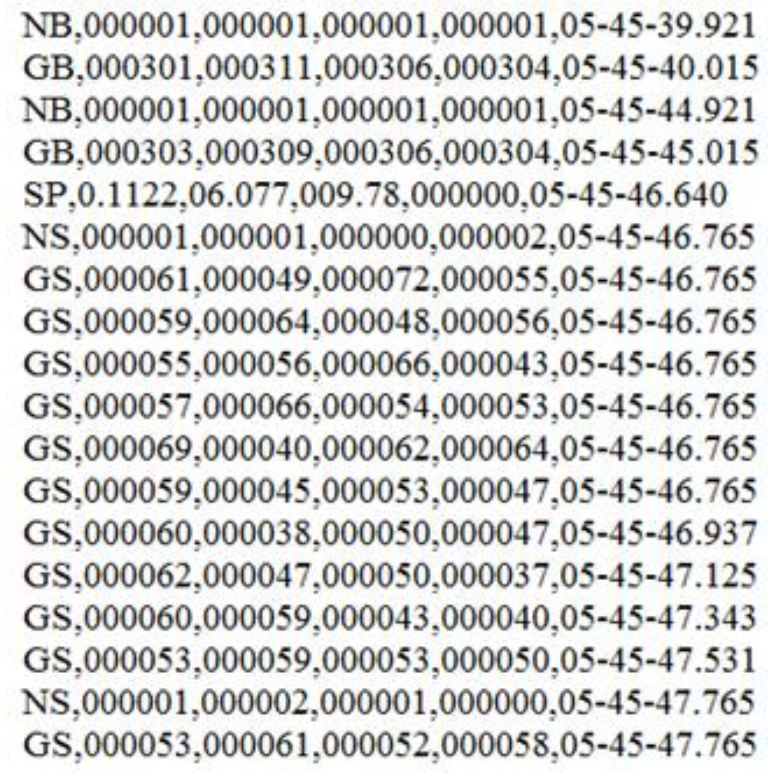

\begin{tabular}{|c|c|}
\hline \multicolumn{2}{|c|}{ Daily File Line Types } \\
\hline GB & Gamma Background \\
\hline NB & Neutron Background \\
\hline GS & Gamma Scan \\
\hline NS & Neutron Scan \\
\hline SP & Speed Message \\
\hline GX & End of Occupancy \\
\hline GA & Gamma Alarm \\
\hline NA & Neutron Alarm \\
\hline SG & Gamma Setting \\
\hline SN & Neutron Setting \\
\hline TT & Tamper Fault \\
\hline TC & Tamper Cleared \\
\hline GH & Gamma High Fault \\
\hline GL & Gamma Low Fault \\
\hline NH & Neutron High Fault \\
\hline
\end{tabular}

Fig. 1. Sample of daily file (left) and line types (right).

\footnotetext{
${ }^{1}$ Train Monitor TM-850 Operations and Service Manual, Doc 5022 Rev B, TSA Systems, Ltd., January 2011. Vehicle Monitor VM-250 Operations and Service Manual, Doc 5039 Rev A, TSA Systems, Ltd., January 2011. Pedestrian Monitor PM-700 Operations and Service Manual, Doc 5038 Rev A, TSA Systems, Ltd., January 2011.
} 
the files received are only a small subset of all possible daily files. Therefore, RPM availability is only representative of the sites that send data to ORNL.

\section{ORNL SLD RPM DATABASE}

ORNL receives approximately 40 gigabytes of data per month in the form of daily files from partner countries. Data is extracted from the daily files and uploaded to the RPM database to organize the data and increase access speeds. It is because of the database that ORNL data analysts can quickly query daily file data and troubleshoot potential issues with the RPMs. The large dataset allows statistically significant conclusions to be drawn about the deployed RPMs. Instead of reading directly from daily files, scripts written at ORNL query the database and extract the data required for calculating availability.

Since ORNL receives a large quantity of data, measures were taken to reduce the amount of data uploaded to the database. As a result, all the data in the daily files is not present in the database. Gamma Background lines are written to daily files every 5 seconds but are only recorded in the database every 10 minutes. Similarly, faults are recorded in the database every 10 minutes, and the precise time of occurrence is not stored. For non-alarming occupancies, only eight entries (four gamma and four neutron) are stored for each occupancy as compared to higher frequency data for alarming occupancies. These differences between the daily files and the database were considered when determining the methodology for calculating availability.

\section{METHODOLOGY}

When calculating RPM availability, ORNL adopted a philosophy to restrict "unavailable" to those times where the RPM was demonstrably inoperable, per the data available. There are many instances where the data received by ORNL is not continuous, but the absence of data is insufficient evidence to consider the RPM as unavailable: RPMs may be turned off when not in use, or daily files may be overlooked in the data collection process. Thus, no credit or penalty is applied for missing data.

For the data that ORNL does receive, daily files are examined against five criteria that provide evidence of a broken RPM component. Only one component of the RPM needs to be broken to make the system unavailable. Availability is calculated by analyzing all the daily files received and determining what fraction of the daily files shows evidence of RPM failure:

$$
\text { Availability }=\frac{\text { Daily File Data Received-Daily File Data with Evidence of RPM Failure }}{\text { Daily File Data Received }}
$$

The criteria used in the availability algorithm were chosen specifically for their ability to differentiate between when an RPM is operable and inoperable and should not be confused with metrics to determine system effectiveness. It is possible an RPM deemed available through the methodology used here may not be capable of effectively detecting special nuclear material (SNM). To accurately define system effectiveness, an algorithm needs to consider RPM alarm rate, staffing requirements for the site, secondary inspection ability, minimum detectable quantity of SNM, accuracy of settings, and numerous other factors that contribute to a site's ability to interdict SNM. Therefore, the availability metric should not be used to determine when a system is effective, but only to calculate when the system is available.

The criteria that provide evidence of an RPM failure are empty daily files, hours of missing data, hours without a background update, fault conditions, and days with two neutron signals constantly measuring zero counts. No single criterion can measure system availability, and these criteria can only approximate 
when an RPM component is broken. However, the methodology uses the data available in the RPM database to form a justifiable and reproducible approximation of availability. Each criterion is described in detail below.

\subsection{EMPTY DAILY FILES}

\begin{tabular}{|c|c|c|}
\hline Criterion & Condition & Decrement \\
\hline Empty & Daily file $<1 \mathrm{kB}$ in size? & 24 hours of availability \\
\hline
\end{tabular}

An empty daily file is defined as a daily file with a file size of less than 1 kilobyte. A file this small is evidence of a communication failure between the RPM and the CAS (Central Alarm Station), which can prevent alarm indicators from being sent to the CAS. As a result, the CAS operator may only be notified of an alarm by the RPM relay (alarm lights and audible annunciator) if the CAS operator is stationed near the RPM. However, the RPM relay is often disabled at Megaports sites, making the CAS the sole provider of alarm indicators. Overall, an empty daily file is evidence of an RPM system whose alarms may not be received by the operator. An empty daily file removes 24 hours from RPM availability.

Empty files are evidence of a communication failure and not a failure of the software that writes the daily file. If the daily file writer was broken, all the daily files for the site would be empty. This has not been observed in the data; usually empty files are seen for particular lanes while the other lanes at the site produce regular daily files.

An empty daily file is treated differently from not receiving a daily file because the creation of the daily file shows there was a failed opportunity to record data. When a daily file is not received by ORNL, nothing is known about the contents of the file. For instance, the RPM may have operated normally, but a poor internet connection may have prevented the file from being transferred. A lack of daily files cannot remove time from system availability since the system may be functioning properly whether or not ORNL receives the file. However, an empty daily file contains information that demonstrates the CAS was operating but was unable to communicate with the RPM.

\subsection{HOURS OF MISSING DATA}

\begin{tabular}{|c|c|c|}
\hline Criterion & Condition & Decrement \\
\hline Hours Missing & Data present each hour? & 1 hour of availability \\
\hline
\end{tabular}

Daily files that are not empty can have periods of time where data is missing within the file. Just as with empty files, this missing data is evidence of a communication failure between the RPM and the CAS. To quantify the missing data, ORNL examines daily files to determine if the timestamp at the end of each line is present for every hour of the day. Every missing hour of timestamps removes 1 hour from RPM availability. ${ }^{2}$ The system is only counted as unavailable when all the lines are missing from the hour. Even if one line is present, the whole hour will be counted as available. This metric ensures the system is

\footnotetext{
${ }^{2}$ Partial days of missing data are measured in terms of whole hours, but evaluating every minute of data was considered. However, it was determined that using a time resolution of 1 minute would likely not increase the accuracy of the availability calculation. This is especially true when the monitor is recording background. Since Gamma Background lines are only stored in the database every 10 minutes, there is no knowledge of whether the system continued to record background between the 10 minute entries. As a result, using a time resolution of 1 minute could imply a detailed precision that is not present in the calculation.
} 
truly unavailable by checking for the presence of multiple lines that should have been uploaded to the database within the hour.

\subsection{HOURS WITHOUT A BACKGROUND UPDATE}

\begin{tabular}{|c|c|c|}
\hline Criterion & Condition & Decrement \\
\hline Hours no Bkgd & GB or NB line present each hour? & 1 hour of availability \\
\hline
\end{tabular}

When the background radiation level is not updated regularly, the alarm threshold can no longer be considered valid for current occupancies. This can result in false alarms when the recorded background is less than the current background and in false negatives (missed sources) when the recorded background is greater than the current background. Broken occupancy sensors, vehicles parking between the RPM pillars, and extreme tailgating are possible pathways to preventing the RPM from updating background appropriately. If an hour in the database does not contain a Gamma Background or Neutron Background line, 1 hour is removed from RPM availability.

\subsection{GAMMA AND NEUTRON FAULTS}

\begin{tabular}{|c|c|c|}
\hline Criterion & Condition & Decrement \\
\hline Faults & GH, GL, or NH present? & 5 seconds of availability / fault \\
\hline
\end{tabular}

When a background line is written to the daily file, a boundary check is performed that can produce Gamma High, Gamma Low, and Neutron High faults. If a gamma or neutron background measurement is out of range, the associated fault line is written to the daily file instead of the regular Gamma Background or Neutron Background line. The purpose of the faults is to notify the operator of unusual background data. Due to the likely invalid background values, when the RPM is in a fault condition it is unable to make a reliable alarm decision based on the detection system that caused the fault. Incorrect background data can lead to false alarms, missed sources, and operator frustration. To warn the operator of this state, the RPM annunciator is triggered every time the RPM is occupied regardless of the count rate during occupancy. Since the RPM cannot perform the task it was designed to do, the RPM is considered unavailable for every 5 second interval labeled Gamma High, Gamma Low, or Neutron High. ${ }^{3,45}$ The cause of the faults is irrelevant with regard to availability since anytime a RPM is in a fault condition, no reliable alarm decisions can be made by the associated detection system.

\footnotetext{
${ }^{3}$ Tamper faults produced from power failure, power restoration, and opening and closing a cabinet are not considered evidence of RPM failure. Routine checks often involve opening the RPM cabinet, and the loss of RPM power is accounted for by checking for missing data.

${ }^{4}$ When the monitor is in occupied mode, fault lines are not written to the daily file, so this time is not removed from availability. The average down time due to faults could be calculated and then extrapolated over the time the RPM is occupied, but assumptions about absent data were avoided when possible. Furthermore, hours of constant occupancy without a background update are already removed from availability, so the daily files that would contribute the most to this positive bias are already accounted for.

${ }^{5}$ Due to limitations of the database, it is possible a pair of Gamma High and Neutron High faults occurring at the same time could decrement availability for 10 seconds when only occurring over a 5 second interval. To minimize this bias, a threshold was established to limit the maximum availability decrement of a 10 minute time period to 10 minutes. In addition, simultaneously triggering Gamma High and Neutron High faults is not a common occurrence.
} 


\subsection{TWO NEUTRON SIGNALS MEASURING ZERO}

\begin{tabular}{|c|c|c|}
\hline Criterion & Condition & Decrement \\
\hline Neutron Failure & Neutron Signal = 0 for detector pair? & 24 hours of availability \\
\hline
\end{tabular}

A Gamma Low fault is built into the RPM fault logic to detect an abnormally low signal from the gamma detectors, which is often indicative of failing detector electronics. Similar logic does not exist for the neutron detectors, since a reading of zero counts is a valid and common background. Consequently, an alternative failure condition is required for quantifying neutron detector failure.

The derivation of the failure condition is complex because the values stored in the database for nonalarming occupancies are not the exact values found in the daily files. As an effort to conserve disk space, only four neutron entries are stored for each non-alarming occupancy. These include the signal values from the last Neutron Background line prior to occupancy, the lowest signal values from the Neutron Scan lines during the occupancy, the highest signal values from the Neutron Scan lines during the occupancy, and the signal values from the last Neutron Background line prior to occupancy (again). As a result, non-zero values are only expected from the highest signal values of non-alarming occupancies and the Neutron Scan lines from alarming occupancies. All of the lines stored in the database used to determine neutron detector failure will be referred to as neutron signal lines.

Vehicle and rail RPMs normally output four neutron signal values on a neutron signal line during occupancy. ${ }^{6}$ When two of the four signal values are repeatedly zero, this is evidence that half the neutron detectors are not functioning correctly. If all the neutron signal lines in the database from one day (with a minimum of 10 neutron signal lines) contain a pair of signal values equaling zero, then the RPM is considered unavailable for the day. ${ }^{7,8}$ If less than 10 neutron signal lines are present in the database during the day, by default the RPM is considered available since the availability of the system is not statistically certain. All pedestrian and conveyor RPMs are not analyzed and considered available by default since certain configurations of these RPMs will only output two non-zero neutron signal values.

For an RPM to be deemed unavailable by means of the neutron failure condition, the same two signal values must be zero for the entire day. If different signal values are zero throughout the day, the system is deemed available:

\footnotetext{
${ }^{6}$ Neutron Scan lines are recorded in the daily file once per second during an occupancy.

${ }^{7}$ Using only Neutron Background lines for calculating availability was considered. Neutron Background lines are written to the daily file every 5 seconds and contain a 20 or 120 second (depending on firmware) average of the measured background. When calculating the average, the result is truncated. This often produces Neutron Background lines that contain all zeros. For instance, if 119 neutron counts were recorded within the last 120 seconds, the neutron background would equate to 0 counts/second. However, since Neutron Scan lines are written to the daily file every second, no division or truncation is required and non-zero numbers are often recorded. For this reason, Neutron Scan lines are considered when determining if a neutron detector is functioning correctly.

${ }^{8}$ Conducting the neutron analysis with a time resolution of 1 hour instead of 1 day was also considered. However, unresponsive neutron detectors do not frequently change between available and unavailable. Typically, the detectors will stay unresponsive until a maintenance team is able to fix them. As a result, analyzing the neutron signals every hour may artificially increase availability; when no neutron signal lines are present in the hour, the system would be deemed available by default, when in actuality the detectors may very well still be unresponsive during the hour without any occupancies. Conducting the neutron analysis on a daily basis provides more opportunity for neutron signal lines to be present in the dataset and for an accurate determination of availability.
} 
Unavailable:

NS, 000000,000000,000001,000002,04-30-42.653

NS,000000,000000,000001,000001,04-30-43.653

NS, 000000,000000,000001,000004,04-50-14.778

NS,000000,000000,000002,000003,04-50-15.762

Available:

NS,000000,000000,000001,000002,04-30-42.653

NS,000001,000000,000000,000003,04-30-43.653

NS, 000001,000002,000000,000000,04-50-14.778

NS,000000,000000,000002,000003,04-50-15.762

A minimum threshold of 10 neutron signal lines is required to ensure a statistical occurrence does not deem the system unavailable. For example, with no threshold, a daily file with a single neutron signal line containing two signal values of zero would deem the system unavailable. The threshold value was determined by sampling all the neutron signal values in the database from 2011 and calculating the fraction of neutron signals with a value of zero. This fraction was used to determine that 10 sequential pairs of zeros are required to ensure the readings of zero are not caused by random statistical events. ${ }^{9}$

\section{EXCLUDED METRICS}

Numerous metrics were considered when defining the RPM availability algorithm, and some were deemed to not accurately represent whether part of the detection system was broken. The justifications for excluding metrics from the algorithm are described in detail below.

\subsection{BAD FORMAT}

A set of rules govern the content of daily files so every file can be processed the same way. Daily files are defined as bad format when more than $1 \%$ of the lines in the daily file do not follow the daily file line convention. Although a daily file not formatted correctly is difficult to post-process, it is not necessarily evidence of RPM failure. Software on the CAS is responsible for writing the data transmitted from the RPM to the daily file. The RPM may be operating correctly, but if the daily file writer is set up incorrectly, the daily file will be in the wrong format. If the majority of the daily file is in the correct format, it is not well understood what component of the system causes single lines to be printed incorrectly. Therefore, badly formatted daily files are not included in the RPM availability algorithm.

\subsection{OVERSIZE FILES}

Daily files are flagged as oversize when their file size is greater than a set limit. Over time, this limit has been adjusted for various reasons but is normally in the range of 5 to 10 megabytes. Using this file size as a metric of system availability was considered but ultimately not incorporated into the algorithm. Daily files often become oversize when the RPM is constantly occupied and many signal lines are written to the daily file. During an occupancy, one Gamma Signal line is written to the daily file every 200 milliseconds as compared to background mode where one Gamma Background line is written to the file every 5 seconds. As a result, extremely large daily files are less likely to contain background lines at appropriate intervals. Large daily files can be caused by a variety of situations including broken occupancy sensors,

\footnotetext{
${ }^{9}$ See Appendix for detailed calculation.
} 
vehicles parking between the RPM pillars, extreme tailgating, and daily files having two timestamps per line. Although some of these situations are evidence of RPM failure, the root cause of the failure is due to a lack of background lines. By spot checking large daily files, files as large as $28.7 \mathrm{MB}$ (double timestamps) and 22.2 MB (single timestamp) were found that included at least one background line. In addition, a file with no background lines could have a small file size due to partial days of missing data. Due to these inconsistencies, it was deemed inappropriate to use file size as a metric for system availability. Instead of file size, every hour of the daily file is checked to determine if the RPM background was updated within the hour. Utilizing this method provides the closest link between the daily file and system availability.

\section{CONCLUSION}

The methodology used to determine RPM availability from daily files is thoroughly defined, and the assumptions made to create the algorithm are described in detail. Since a set of well-defined metrics define the availability algorithm, RPM availability is a reproducible value that does not require the subjective view of data analysts. The algorithm for calculating RPM availability from SLD daily files can be utilized to justifiably track the operation of RPMs across the program. 



\section{APPENDIX A}





\section{A.1 CALCULATION OF MINIMUM REQUIRED NEUTRON SIGNAL LINES}

The probability of a neutron signal value of zero occurring by means of random statistical events (i.e., chance alone) was estimated by sampling all the available data from 2011. The fraction of all the neutron signal values in the database with a value of zero was 0.45. However, this method assumes all RPM configurations have an equal likelihood of measuring neutron signal values of zero. This is unlikely since many factors such as the number of He-3 tubes and the altitude of the installation influence the neutron signal value. Consequently, a histogram of daily average neutron signal values recorded during occupancies (Fig. A.1) was created to determine the extent of variation between RPM configurations. Since daily averages are presented, each data point is representative of the average neutron signal value from a particular lane. Averaging the data in this manner allows neutron signal value trends to be exposed.

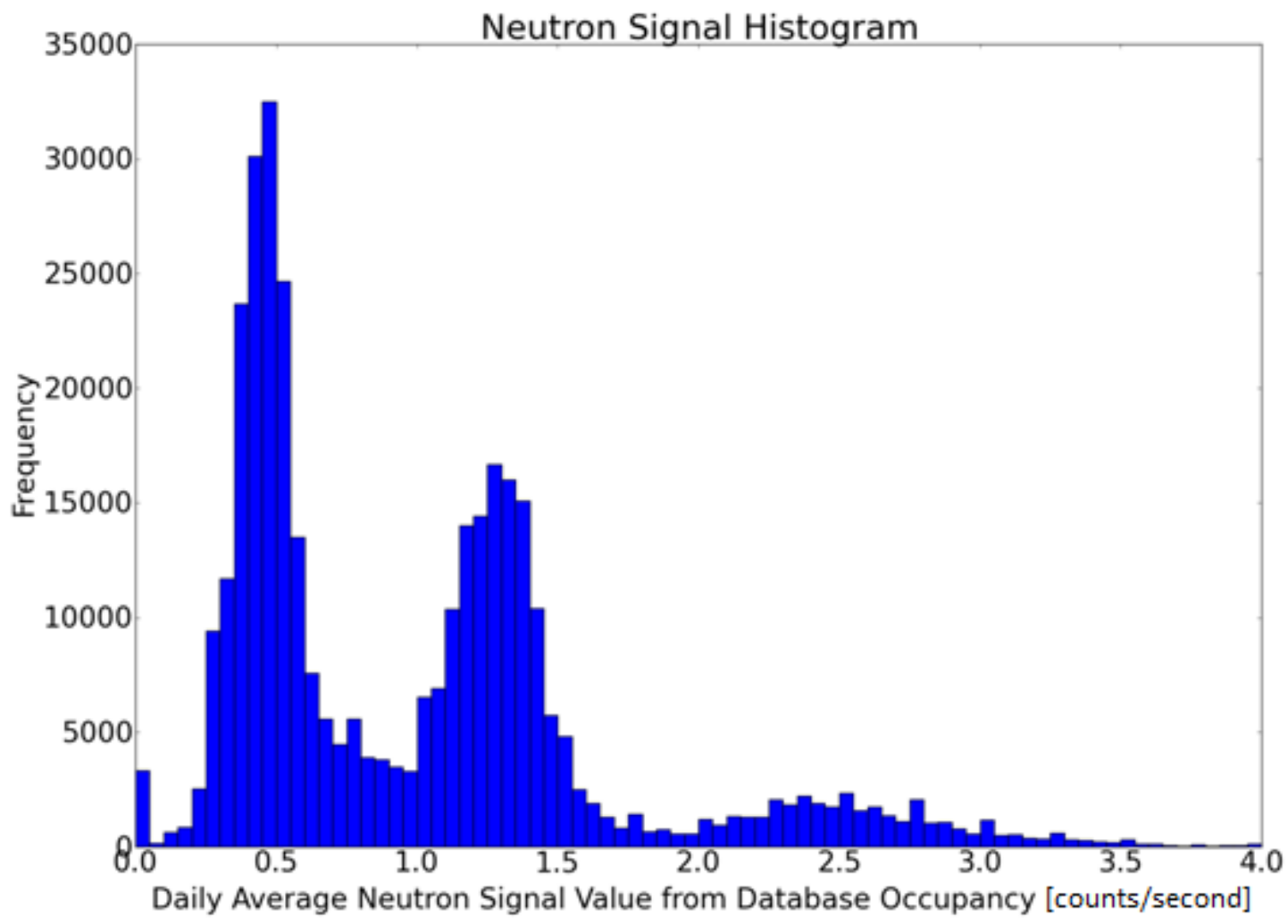

Fig. A.1. Histogram of daily average neutron signal values in 2011.

The distinctive peaks are evidence the average neutron signal value is dependent on the RPM configuration and that all RPM configurations will not experience the same probability of a neutron signal value measuring zero. ${ }^{10}$ However, the peaks in the distributon do not vary so greatly that it is unreasonable to sample the entire database to estimate the probability of measuring a neutron signal value of zero. The histogram illustrates the inherent uncertainty in this calculation and provides an explanation to why the probability of 0.45 is an estimation.

Given the probability, $\mathrm{p}$, of one neutron signal value measuring zero, the probability, $\mathrm{P}$, of a sequence of $\mathrm{L}$ trials also measuring zero can be determined:

\footnotetext{
${ }^{10}$ Determining the RPM configurations responsible for these trends is outside the scope of this work.
} 


$$
p^{L}=P
$$

However, the probability of a sequence of zeros in at least two of the four neutron signal values is in question. A binomial distribution is used to represent a combination of possible successful outcomes and is set equal to the acceptable probability of occurrence, one in one million. The successful outcomes include two of four neutron signal values measuring zero, three of four measuring zero, and four of four measuring zero.

where

$$
\frac{n !}{k !(n-k) !}\left[P^{k}(1-P)^{n-k}\right]=x
$$

$k=$ number of successes (number of neutron signal values measuring zero),

$n=$ number of events (number of neutron signal values on a neutron signal line),

$P=$ probability of success for any single event $\left(p^{L}\right)$,

$x=$ probability of at least two of four neutron signal values measuring zero in a sequence of $L$ trials.

$$
\begin{gathered}
6\left[P^{2}(1-P)^{2}\right]+4\left[P^{3}(1-P)^{1}\right]+P^{4}=1 * 10^{-6} \\
P=4 * 10^{-4}=p^{L}
\end{gathered}
$$

This probability is then used to determine the required number of trails in the sequence.

$$
\begin{gathered}
p^{L}=P \\
0.45^{L}=4 * 10^{-4} \\
L=10
\end{gathered}
$$

As a result, at least 10 neutron signal lines must be present in the database to deem the system unavailable by means of the neutron failure criterion. To make the failure condition more conservative, more neutron signal lines may be analyzed. 


\section{A.2 PROGRAMMING SOURCE CODE FOR ALGORITHM}

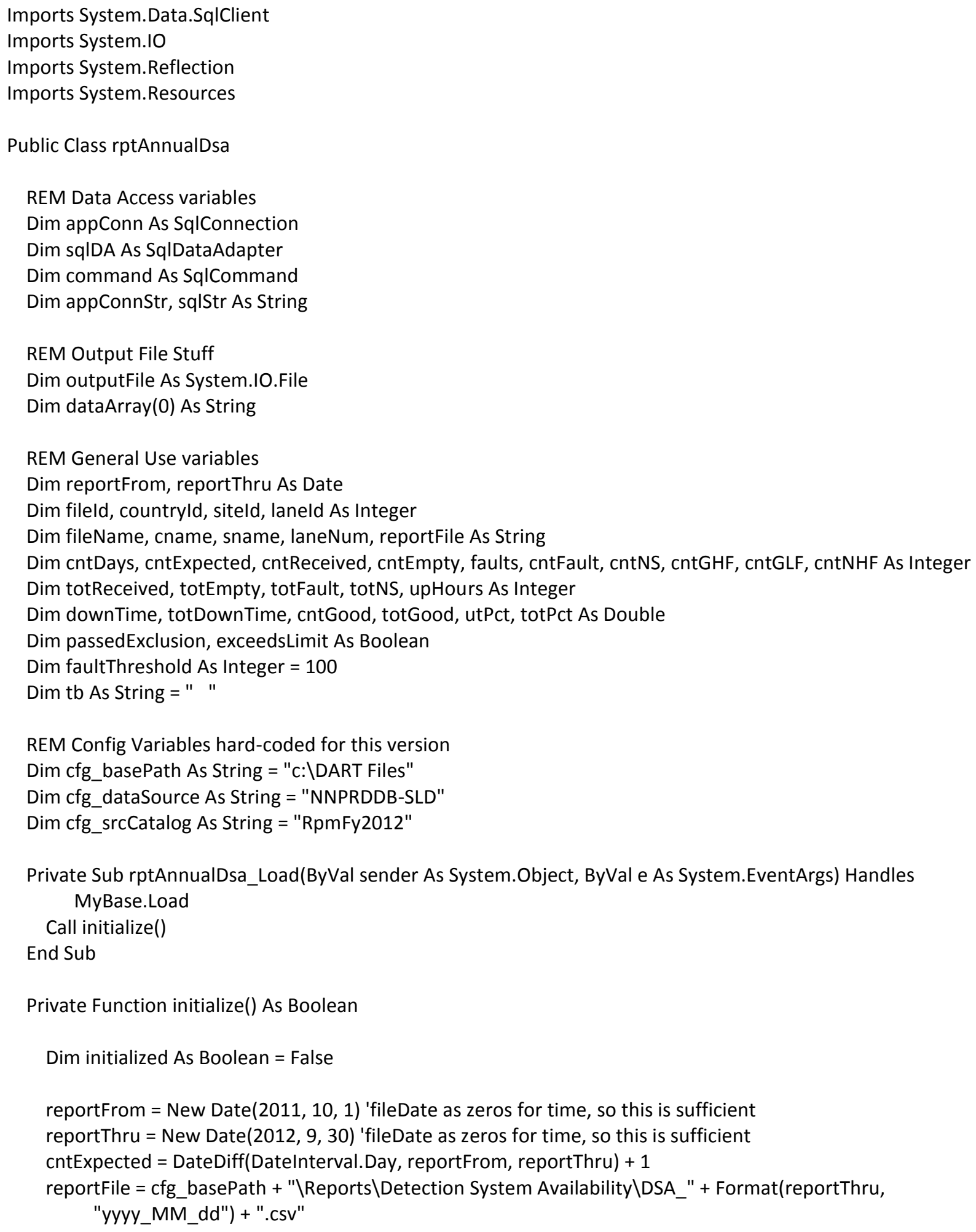


REM Derive source connection info

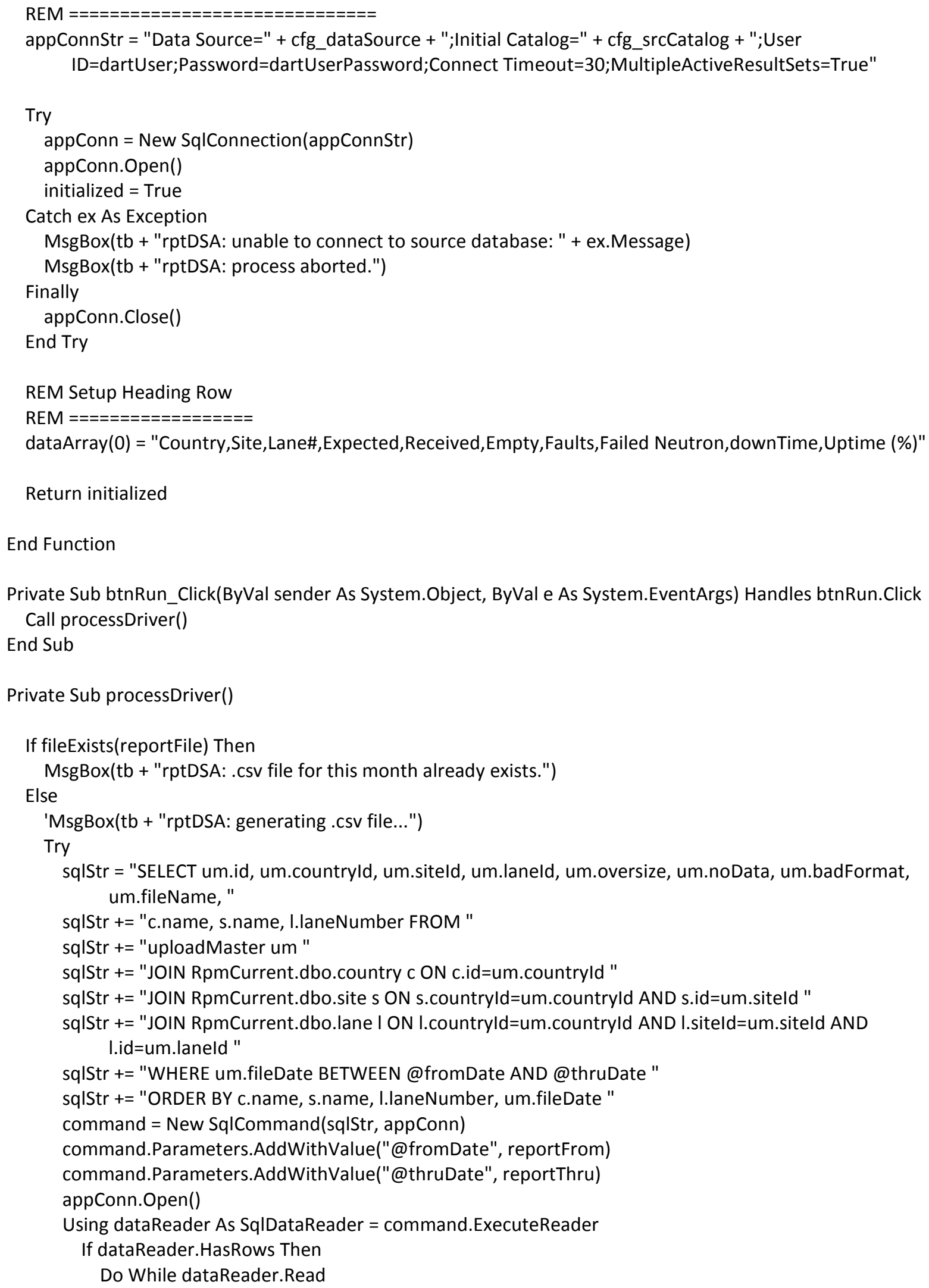




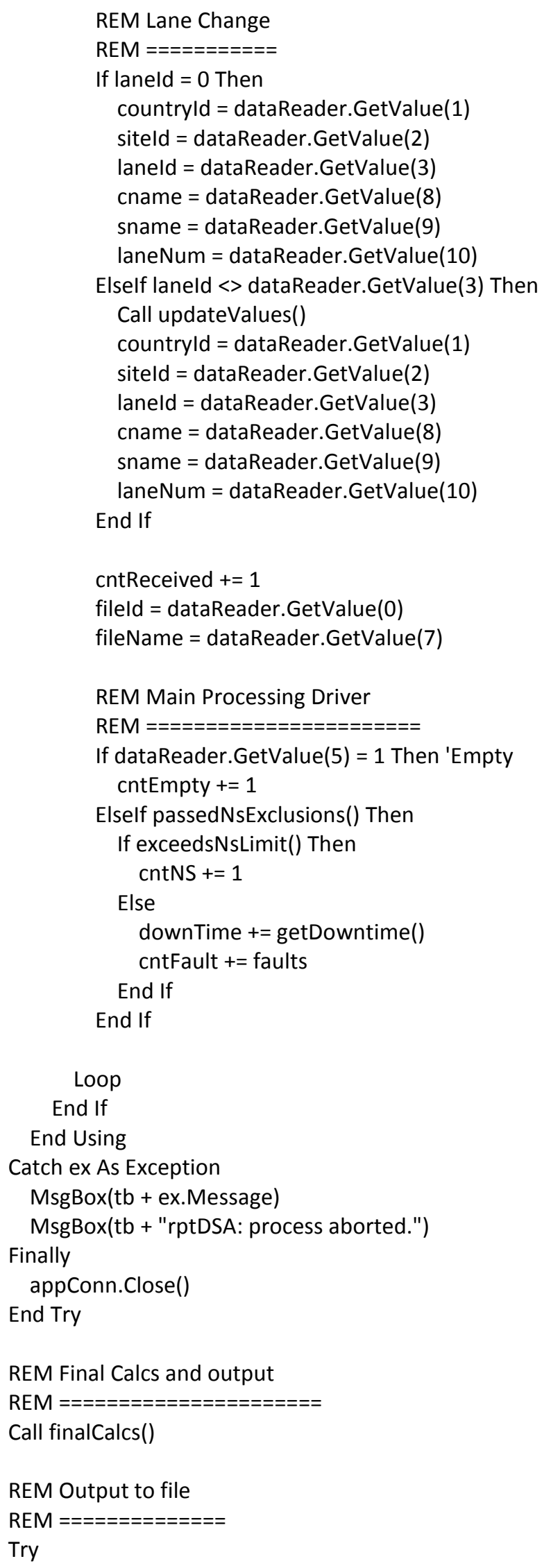




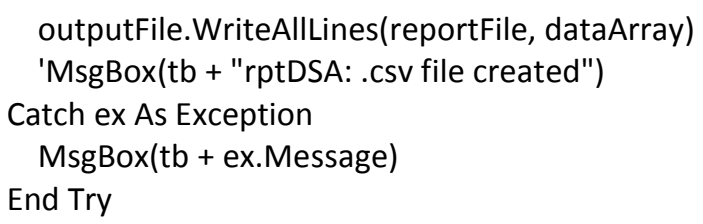

End Sub

Private Function passedNsExclusions() As Boolean

passedExclusion $=$ True

REM Mobile Detection Sensor is excluded

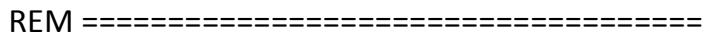

If InStr(fileName, "MDS") > 0 Then 


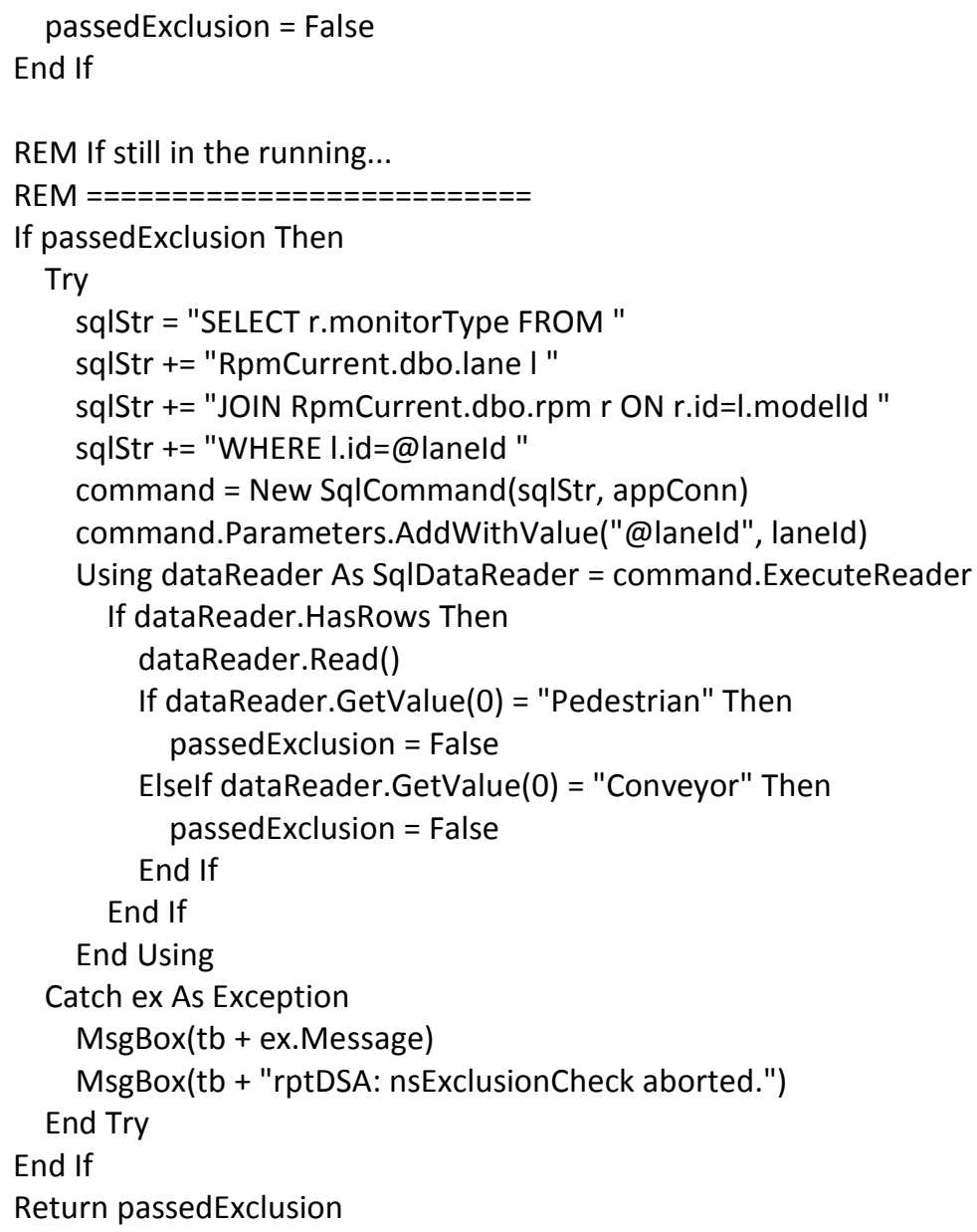




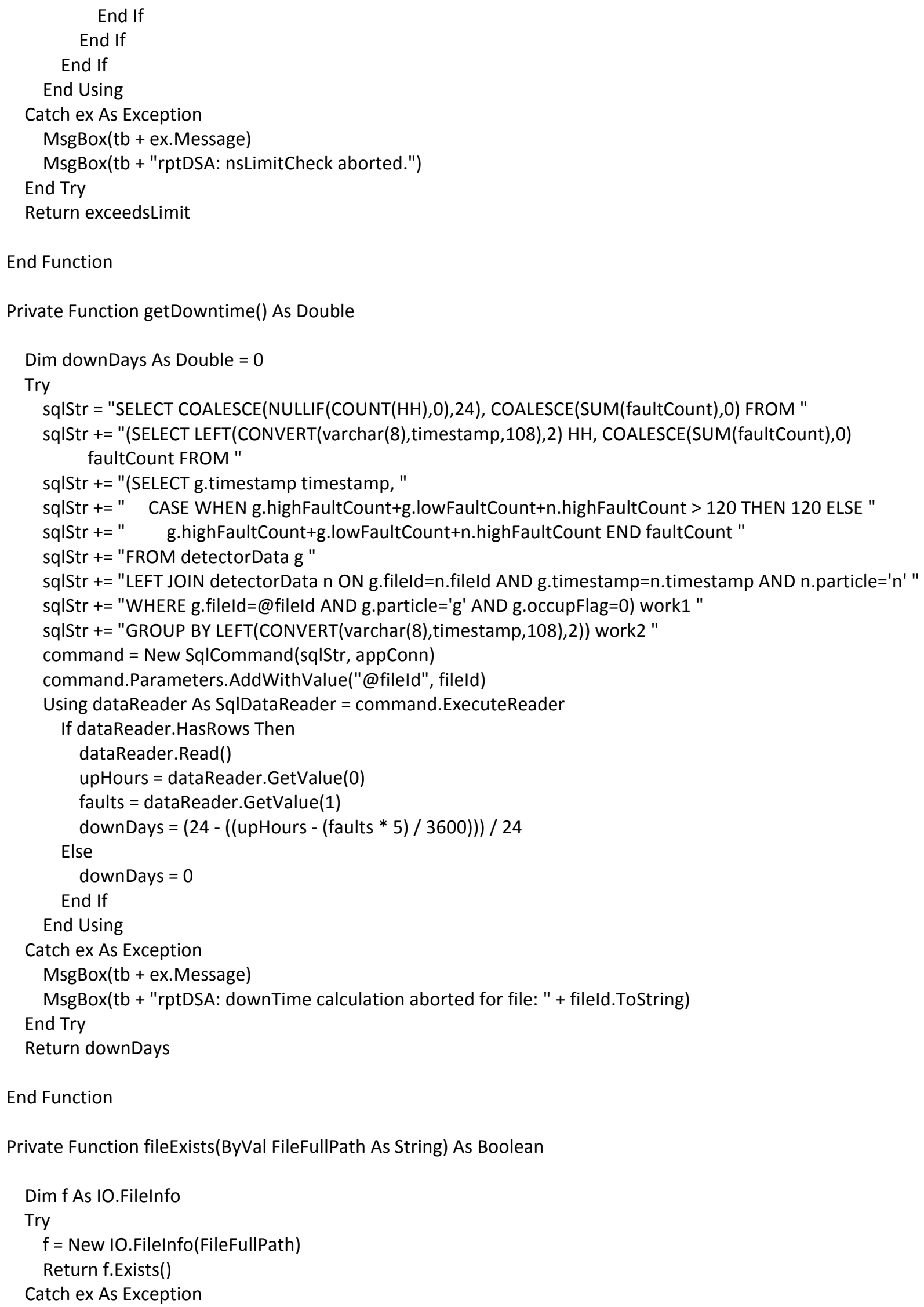

End Function

Private Function fileExists(ByVal FileFullPath As String) As Boolean

Dim f As IO.Filelnfo

Try

$f=$ New IO.Filelnfo(FileFullPath)

Return f.Exists()

Catch ex As Exception 


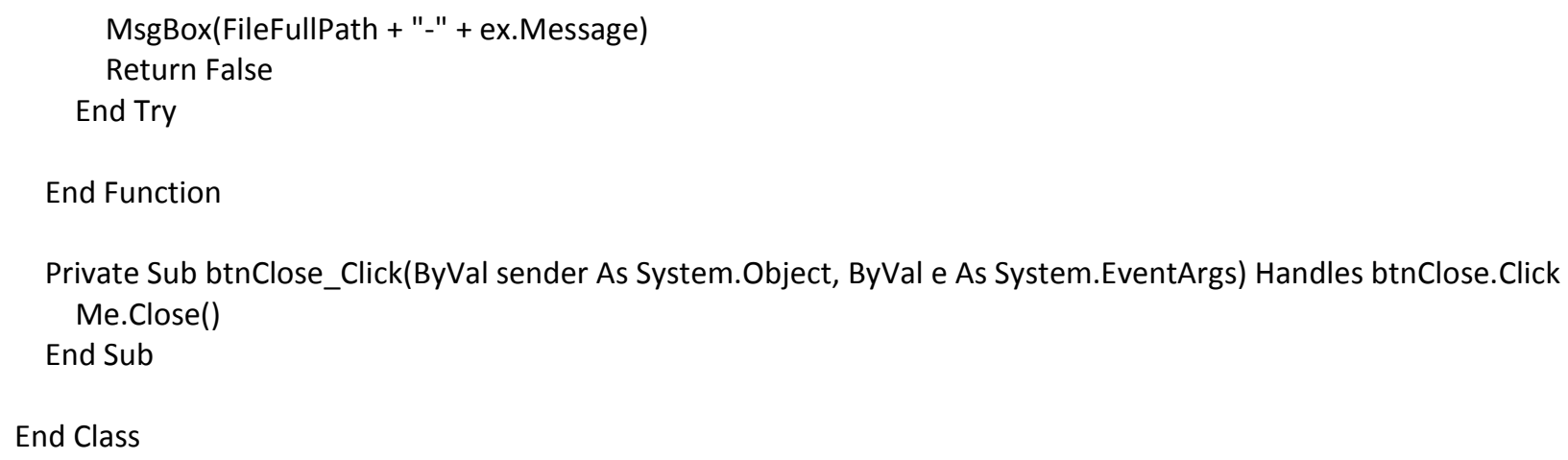

